\title{
Why was this child not brought?
}

\author{
Michael F E Roe, ${ }^{1}$ Jane V Appleton, ${ }^{2}$ Catherine Powell ${ }^{3}$
}

How do we react to the missed appointment? It is a busy clinic (is there any other type?) and the first reaction is likely to be relief. Then there is the realisation that some thought may need to be applied to the child who was not brought. Then there is the remembrance that there is a policy to be followed. Perhaps, it would have been easier if the child had come to the clinic...

There are a multitude of issues that derive from a missed appointment. It has implications for the child or young person, the parent/carer, the health practitioner for whom the child had the appointment, the referrer, the Trust or other health provider, for Commissioners and possibly for the Care Quality Commission and Local Safeguarding Children Boards among others. It is easy to lose sight of the child or young person in all these.

Even the terminology is open to debate. We have previously argued that 'Was Not Brought' (WNB) was a more appropriate nomenclature to use than 'Did Not Attend' (DNA) when applied to children and young people ${ }^{1}$ and that the reconceptualisation of the DNA as WNB would lead to positive interventions to safeguard and promote the welfare of children. ${ }^{2}$ Munro has also commented that the change from DNA to WNB is a simple mechanism for triggering a different reaction. ${ }^{3}$ These three articles stress the need to ask why the child or young person was not brought and to consider this from the child's perspective. We recommend that a WNB policy includes a statement such as 'When appropriate, children and young people should be directly involved in their own health care and therefore they should be involved when they are not brought for appointments'.

Writing a guideline to meet the needs of all stakeholders involved is difficult. Writing a guideline to meet every eventuality requires, at the very least, consideration of all the likely scenarios. Is it possible to generalise about missed

\footnotetext{
${ }^{1}$ University Hospital Southampton NHS Foundation Trust, Southampton, UK; ${ }^{2}$ Faculty of Health and Life Sciences, Department of Psychology, Social Work and Public Health, Oxford Brookes University, Oxford, UK; ${ }^{3}$ Faculty of Health Sciences, University of Southampton, Southampton, UK
}

Correspondence to Dr Michael F E Roe, University Hospital Southampton NHS Foundation Trust,

Southampton S016 6YD, UK; michael.roe@uhs.nhs.uk appointments when, in reality, every situation is likely to be unique?

Arai et $a l^{4}$ have published an article reviewing WNB guidelines from National Health Service (NHS) organisations that are accessible on an open website. The methodology of this study has led to a very small sample size $(<8 \%$ of NHS organisations were included) but, despite this, the study makes some pertinent, if very general, observations and recommendations about the creation and implementation of WNB guidelines. Using a similar approach that sought to review NHS and independent providers' policies in acute and community settings across the UK, as part of a wider study, Appleton et al (Professional and organisational responses to children's missed health care appointments: a child protection concern? Pilot work-Final Report to the NSPCC. September 2014 (unpublished)) concluded that organisational policies were hosted on intranet, rather than internet websites.

Previously, Arai et al $l^{5}$ have published a scoping study to map the literature around WNB and identify gaps in the research. This study identified a number of factors affecting attendance at appointments. These factors can be summarised as answering the question of why the child or young person was not brought to the appointment. One factor not mentioned, but has been identified in other studies, is the child or young person and/or the parent/carer not knowing the reason for the appointment. ${ }^{6}$ On reflection, this seems quite surprising, but is probably more common than realised or than the healthcare providers would like to admit. It would be interesting to know how many people do attend for health consultations without really understanding why the appointment has been made.

It is worth pointing out that cancellation of an appointment by a parent or carer is often considered by health professionals as different to not being brought to an appointment. However, from the child's perspective, the distinction is less clear cut. In both situations, the child is not seen by a healthcare professional. ${ }^{3}$ As with other reasons for the child not being seen, this can sit on the spectrum between being in the child's best interests and raising significant safeguarding concerns.

In addition to trying to understand why children and young people are not brought to appointments, it is worth asking which professional is primarily responsible. For follow-up appointments, this would seem straightforward, but for the first appointment, for example, general practitioner referral to general paediatrician, who should consider why the child was not brought? Can there be a collaborative approach agreed between referrer and provider of appointment. Does this require a guideline that can cross over between different NHS providers? The recent Royal College of General Practitioners/ National Society for the Prevention of Cruelty to Children toolkit (see http://www.rcgp.org.uk/ clinical-and-research/clinical-resources/thercgp-nspcc-safeguarding-children-toolkitfor-general-practice.aspx) makes the recommendation that 'primary care practices should have procedures in place for identifying and following up children who do not attend scheduled appointments with the Practice or with other agencies such as therapies, secondary or community care'. However, there is no detail about how this might be achieved. Must primary care rely on information from the appointment that the child or young person WNB? Are there expectations beyond this? How would it work for referrals between different secondary care providers? We know that currently we do not have the systems in place to achieve this. However, does identifying and following up children equate to asking the question 'Why was this child not brought?'

What research and general principles will struggle to answer is what is happening for the individual child? As stressed already, every WNB is different and building up a complete and accurate picture of why the child or young person WNB may be time consuming and ultimately impossible. It is very likely that, in the vast majority of these situations, the health professional caring for the child or young person will have an incomplete picture of the case. It is in this situation, as in all other areas of health and social care, where professional judgement needs to be made.

Professional judgement is fraught with uncertainty and complexity but, in contrast to the generalisations of guidelines and policies, may be more responsive to the individual situation and be a more appropriate mechanism to ensure the correct response to the child or young person WNB. Policies and guidelines may provide some suggestions or recommendations that should allow the professional to make a judgement on the individual case, particularly regarding any safeguarding concerns. 


\section{Editorials}

Munro has commented that it is important to avoid just adding another set of prescriptions to professionals' workloads and another layer of guilt for not living up to best practice at all times. ${ }^{3}$ The need for health professionals to understand why an individual child was not brought to their appointment is recognised as important but we require the necessary systems to achieve this and to be able to ask the question 'Why was this particular child or young person not brought to this appointment?'

Competing interests None.

Provenance and peer review Commissioned; internally peer reviewed.
To cite Roe MFE, Appleton JV, Powell C. Arch Dis Child 2015;100:511-512.

Received 6 February 2015

Accepted 5 March 2015

Published Online First 31 March 2015

\section{Ginked}

http://dx.doi.org/10.1136/archdischild-2014-307294

Arch Dis Child 2015;100:511-512.

doi:10.1136/archdischild-2014-307856

\section{REFERENCES}

1 Roe M. WNB versus DNA: why children cannot 'not attend'. Brit Med J 2010;341:1052.
2 Powell C, Appleton JV. Children and young people's missed health care appointments: reconceptualising 'Did Not Attend' to 'Was Not Brought' — a review of the evidence for practice. J Res Nurs 2012;17: 181-92.

3 Munro E. Review: children and young people's missed health care appointments: reconceptualising 'Did Not Attend' to 'Was Not Brought' - a review of the evidence for practice. J Res Nurs 2012;17: 193-4.

4 Arai L, Stephenson T, Roberts H. The unseen child and safeguarding: 'Did not attend' guidelines in the NHS. Arch Dis Child 2015;100:517-20.

5 Arai L, Stapley S, Roberts H. 'Did not attends' in children 0-10: a scoping review. Child Care Health Dev 2014;40:797-805.

6 Pesata V, Pallija G, Webb AA. A descriptive study of missed appointments: families' perceptions of barriers to care. J Pediatr Health Care 1999;13:178-82. 